\title{
Directed forgetting shares mechanisms with attentional withdrawal but not with stop-signal inhibition
}

\author{
Jonathan M. FawCETt ANd Tracy L. TAYlor \\ Dalhousie University, Halifax, Nova Scotia, Canada
}

\begin{abstract}
To explore the mechanisms underlying the ability to intentionally forget, the present study combined an itemmethod directed forgetting paradigm with tasks that measure stop-signal inhibition (Experiments 1 and 2) and inhibition of return (IOR; Experiment 2). Following each study-phase instruction to remember (R) or forget (F), a target was presented centrally (Experiment 1) or to the left or right in the visual periphery (Experiment 2); the target required a speeded response that was sometimes countermanded by a central stop signal. Although stopsignal reaction times were unaffected by the preceding memory instruction (or relationship with word-target location), $\mathrm{F}$ instructions improved stopping and delayed responses. Replicating previous findings in the literature, significant IOR was observed following F instructions but not following R instructions (Experiment 2). These findings suggest that intentional forgetting is an active cognitive process that more likely engages attentional mechanisms related to orienting than those related to stop-signal inhibition.
\end{abstract}

Forgetting is often conceptualized as a memory failure. Although it is true that the inability to produce a critical bit of information at the opportune moment may have undesirable consequences (e.g., looking foolish in front of one's dissertation committee), the inability to suppress an irrelevant bit of information at an inopportune moment can be similarly disastrous. In fact, the capacity to "prune" memories that have outlived their usefulness (e.g., where you parked yesterday) can facilitate the retrieval of relevant memories (e.g., where you parked today). This sort of strategic forgetfulness has been labeled intentional forgetting and can be studied in the laboratory using a paradigm known as directed forgetting.

A typical item-method directed forgetting task ${ }^{1}$ is composed of two phases: (1) the study phase, during which participants are presented with a series of words, one at a time, each followed randomly - usually after a brief delay-by an instruction to remember $(\mathrm{R})$ or forget $(\mathrm{F})$ the word, and (2) the subsequent test phase, during which participants are then asked to recall or recognize all previously presented study words. A directed forgetting effect is defined as better recall and/or recognition of $\mathrm{R}$ words than of $\mathrm{F}$ words (Bjork, 1972; for a review, see MacLeod, 1998).

Two theories have emerged to account for the fate of the F-instructed items. According to the selective rehearsal account, participants refresh the word in working memory via maintenance rehearsal (cf. Greene, 1987) until the presentation of the R or F instruction. Following an R instruction, participants engage in elaborative processing of the word (but see Golding, Roper, \& Hauselt, 1996); follow- ing an F instruction, participants simply drop the word from their rehearsal set and allow its representation to decay. Because no strategies are posited following an $\mathrm{F}$ instruction, this account of item-method directed forgetting essentially views forgetting as the absence of rehearsal.

In contrast, Zacks and Hasher (1994; see also Hasher \& Zacks, 1988) proposed that forgetting requires the engagement of cognitive mechanisms to actively withdraw attention from the representation of $\mathrm{F}$ words during encoding. They further argued that one consequence of this attentional withdrawal is that $\mathrm{F}$ items are inhibited so that they cannot regain easy access to working memory at retrieval. Even though there has been no evidence to support the claim that $\mathrm{F}$ items are inhibited from reentering working memory at retrieval (see Marks \& Dulaney, 2001), its inclusion in Zacks and Hasher's characterization of forgetting has led to their view being referred to as the attentional inhibition hypothesis. For our purposes, the consequences of active attentional withdrawal are less interesting than the implications of the withdrawal itself. Positing the withdrawal of attention from $\mathrm{F}$ items characterizes forgetting not as a passive process, but as an active one. By actively purging and reducing the accessibility of study words following an $\mathrm{F}$ instruction, participants are discouraged from affording these words any additional rehearsal—-providing a potential functional mechanism for enabling focused rehearsal of R words. Although this means that forgetting is initially cognitively demanding (during expulsion of the $\mathrm{F}$ item from working memory), once the $\mathrm{F}$ items are successfully expunged, limited-capacity resources are freed 
for processing relevant $(\mathrm{R})$ rather than irrelevant $(\mathrm{F})$ items (see Roediger \& Crowder, 1972). ${ }^{2}$

Although some studies have argued that inhibitory processes like those hypothesized by Zacks, Radvansky, and Hasher (1996) function passively (similar to spreading activation; Neumann \& DeSchepper, 1992), others have shown that inhibitory processing can be effortful (see Engle, Conway, Tuholski, \& Shisler, 1995). To test whether instantiating an instruction to forget is initially demanding of cognitive resources (i.e., at encoding), Fawcett and Taylor (2008) embedded a secondary probe task within an item-method directed forgetting paradigm. Visual-detection probes were presented at varying stimulus onset asynchronies (SOAs) relative to the $\mathrm{R}$ and $\mathrm{F}$ instructions; detection-probe reaction times (RTs) were used as an index of cognitive load (see Kahneman, 1973). Probe RTs were slower following $F$ instructions than following $\mathrm{R}$ instructions, implying that instantiating an $\mathrm{F}$ instruction was not only cognitively demanding but that it was in fact more cognitively demanding than instantiating an $\mathrm{R}$ instruction. Moreover, probe RTs were longer following F words that were successfully forgotten than following F words that were remembered. R-trial probe RTs were unrelated to subsequent memory performance, suggesting that the observed $\mathrm{F}>\mathrm{R}$ RT difference was associated with intentional, as opposed to unintentional, forgetting (see also Wylie, Foxe, \& Taylor, 2008). Participants also made fewer false alarms on no-probe catch trials following $\mathrm{F}$ instructions than on those following $\mathrm{R}$ instructions, suggesting a link between forgetting and response inhibition (see, e.g., Logan, 1994).

Thinking along these lines, Hourihan and Taylor (2006) suggested that an item-method $\mathrm{F}$ instruction is analogous to a stop signal in that it countermands the execution of an unwanted behavior-in this case, rehearsal of the F-instructed words (see Anderson, 2003). In a typical stop-signal paradigm, participants are presented with a target requiring a speeded overt response. On some portion of trials, they receive a countermanding instruction (the stop signal) to withhold this prepotent response. The ability to do so is related to the delay between the onset of the target (the go signal) and the presentation of the countermanding instruction (the stop signal): The longer this stop-signal delay (SSD), the more likely it is that an unwanted prepotent response will be executed.

Performance in a stop-signal task is modeled as a race between the go process initiated by target onset and the stop process initiated by stop-signal onset. The notion is that when the go process "outruns" the stop process (such as when there is a large head start imposed by a long delay between the target and the stop signal), the unwanted prepotent response will be executed. When the stop process "outruns" the go process, this response will be successfully inhibited. The speed of the go process is directly measured on trials in which no stop signal is presented (i.e., the go trials). The speed of the stop process is estimated using the probability of inhibiting a response during stop trials (i.e., trials containing a stop signal) and RTs during go trials. The resulting measure, stop-signal reaction time (SSRT), is conceptualized as the speed of the covert mechanism that operates to stop the execution of an unwanted response (for a review, see Logan, 1994).

Relating these methods to item-method directed forgetting, Hourihan and Taylor (2006) demonstrated that stopping covert rehearsal following an $\mathrm{F}$ instruction in an item-method task is akin to stopping the overt execution of a prepotent motor response. They presented participants with a list of words, one at a time, each of which was to be retained for subsequent recognition; on a random portion of trials, this default instruction to remember was countermanded, and participants were instead instructed to forget the word. F instructions were presented at SOAs of 1, 3, or $6 \mathrm{sec}$ relative to study-word onset. Results showed that F-word recognition performance increased as a function of the word-instruction SOA. This finding is analogous to the relationship between SSD and recognition performance that was observed by Logan and colleagues (Logan, 1983, 1985; Logan \& Barber, 1985; Zbrodoff \& Logan, 1986).

Although Hourihan and Taylor (2006) demonstrated that an $\mathrm{F}$ instruction could function in a manner analogous to a stop signal (yielding similar behavioral results), it is uncertain whether they share underlying mechanisms. The present experiments explored the relationship between item-method directed forgetting and stop-signal inhibition. Each experiment utilized an item-method paradigm wherein a secondary RT target was presented following each study-phase memory instruction, sometimes accompanied by an instruction to countermand the response. Experiment 1 showed that an instruction to forget increased the probability that participants would successfully inhibit an unwanted response by slowing RTs (as opposed to speeding SSRTs). This suggests that stopping an unwanted covert behavior (rehearsal of an F item) depends on cognitive mechanisms that are distinct from those used to stop an unwanted overt behavior (execution of a prepotent motor response). Experiment 2 extended these findings by presenting words and targets in the visual periphery to permit exploration of visuospatial attentional withdrawal in directed forgetting. Experiment 2 showed that inhibition of return (IOR) - an effect that is typically revealed only following attentional withdrawal-was larger following $\mathrm{F}$ instructions than following $\mathrm{R}$ instructions.

Together, these experiments confirmed the active nature of forgetting, and their results speak to the attentional system that may be engaged by this active process.

\section{EXPERIMENT 1}

In the first experiment, a stop-signal task was embedded within the study phase of an item-method directed forgetting paradigm. We reasoned that the mechanism engaged to stop covert rehearsal following an $\mathrm{F}$ instruction might also prevent the overt execution of an otherwise unrelated response. Each study-phase trial contained a secondary stop-signal task following the memory instruction. If $F$ instructions enact a mechanism similar to a stop signal (acting on a cognitive, as opposed to motor, response), participants should be better at stopping following $\mathrm{F}$ instructions than following $\mathrm{R}$ instructions. This would be evidenced by an increased likelihood of suc- 
cessfully inhibiting the prepotent motor response and by a corresponding decrease in SSRT (i.e., a speeding of the covert stopping mechanism).

\section{Method}

\section{Participants}

Twenty-five undergraduate students (18 female, 7 male) enrolled at Dalhousie University participated in this experiment for course credit.

\section{Stimuli and Apparatus}

All experimental procedures utilized PsyScope 5.1.2 (Cohen, MacWhinney, Flatt, \& Provost, 1993) loaded on a Macintosh G4400 computer running OS 9. Stimuli were presented on a 17-in. $1,024 \times 768$ Macintosh Studio Display or a ViewSonic PT775 color monitor viewed from approximately $57 \mathrm{~cm}$; responses were recorded via a standard Macintosh USB keyboard. Text was presented against a white background and in black Helvetica 24-point font; go and stop signals were green- and red-filled circles, respectively, outlined in a 4-point black border, and they were $1.5^{\circ}$ of visual angle in diameter. $\mathrm{R}$ and $\mathrm{F}$ memory instructions consisted of two 400-msec tones (high, $1170 \mathrm{~Hz}$; low, $260 \mathrm{~Hz}$ ) presented via built-in computer speakers.

Three hundred twelve nouns were randomly selected by the Paivio, Yuille, and Madigan Word List Generator (www.math.yorku .ca/SCS/Online/paivio/). These words were presented in lowercase letters and had an average Kučera-Francis (1967) word frequency of 80.44 , an imagery rating of 5.11, and a concreteness rating of 4.98 . The words were 3-5 letters in length, with a mean of 4.31 letters and 1.13 syllables. Prior to running each participant, the master word list was randomly divided into $\mathrm{F}(n=78), \mathrm{R}(n=78)$, and foil $(n=$ 156) word lists.

\section{Procedure}

Participants were instructed that they would receive a number of trials containing a word followed by an R or F instruction. For half of the participants, the high-frequency tone served as the R instruction, and the low-frequency tone served as the F instruction; the opposite designations were used for the remaining participants. Instructions indicated that recognition memory would be tested at the end of the experiment, but participants were not explicitly informed that both $\mathrm{R}$ and $\mathrm{F}$ words would be tested.

Participants were also informed that (1) following the memory instruction on each trial, a green-filled circle (go signal) would appear, requiring a speeded detection response, (2) on some trials the greenfilled circle would change into a red-filled circle (stop signal) after a variable delay, and (3) if possible, they should withhold responses for any trials in which this color change (green to red) occurred.

Practice phase. Participants practiced the task until the experimenter felt confident that they understood the task demands. Practice trials were identical to study-phase trials (described below), except that the study word was replaced by a string of five Xs.

Familiarization phase. At the start of the experiment, participants were presented with eight tone-familiarization trials. Each trial presented a visual fixation (a plus sign) for $1,000 \mathrm{msec}$, followed with equal probability by a high or low tone for $400 \mathrm{msec}$ accompanied by the relevant verbal descriptor printed on the computer monitor (e.g., "remember the word") for 3,000 msec.

Study phase. As depicted in Figure 1, each study-phase trial began with a centralized fixation stimulus (a plus sign) lasting $1,500 \mathrm{msec}$. This stimulus was replaced by a word for $1,000 \mathrm{msec}$, after which the central fixation stimulus reappeared for 3,350 msec. The word was drawn randomly, without replacement, from the $\mathrm{R}$ or F word list. At 2,000 msec following the study word, the corresponding ( $\mathrm{R}$ or $\mathrm{F}$ ) memory instruction (high or low tone) was presented for $400 \mathrm{msec}$. The go signal was presented 1,400 $\mathrm{msec}$ following the onset of the memory instruction. ${ }^{3}$ On a random half of the trials (go trials), this go signal remained visible for $1,000 \mathrm{msec}$; participants were required to report its detection by pressing the space bar as quickly as possible. On the other half of the trials (stop trials), the green-filled circle (the go signal) was replaced by an otherwise identical red-filled circle (the stop signal); upon receipt of the stop signal, participants were required to withhold their response, if possible. The onset of the stop signal occurred with equal probability at one of three SSDs measured relative to the onset of the go signal: 200,400 , or $800 \mathrm{msec}$ (see Ivanoff \& Taylor, 2006). The total duration of the go and stop signals summed to $1,000 \mathrm{msec}$. Each trial ended with an enforced intertrial interval of 2,100 $\mathrm{msec}$, resulting in a total trial duration of $9,000 \mathrm{msec}$.

Overall, 156 study trials were presented. Of these, 78 were go trials and 78 were stop trials. The 78 go trials were distributed equally over $\mathrm{R}$ and $\mathrm{F}$ conditions. The 78 stop trials were distributed in such a way that there were $13 \mathrm{R}$ and $13 \mathrm{~F}$ words at each of the three SSDs.

Four buffer trials at the beginning and four at the end were included to minimize recency and primacy effects. Buffer words were the same for all participants and were invariably followed by an R instruction; these items were not tested at recognition.

Recognition phase. Following the study phase, participants were presented with the $\mathrm{R}$ and $\mathrm{F}$ words from the study trials, intermixed with an equal number of unstudied foil words. Instructions presented at the top of the computer screen throughout this phase informed participants that they should attempt to recognize all words that were presented during study, regardless of memory instruction. Words were drawn randomly, without replacement, and were presented one at a time on the computer screen in blue print. Participants pressed the " $y$ " key (a yes response) to indicate that a word had been previously presented in the study phase (i.e., R and F words) or the " $n$ " key (a no response) to indicate that a word had not been previously presented (i.e., foil words). Responses appeared in a text box on the screen and could be self-corrected until the space bar was depressed to submit the response.

\section{Results}

The data from 6 participants were excluded because of lower than $50 \%$ accuracy in either the $\mathrm{R}$ or $\mathrm{F}$ go condition, or because of lower than $5 \%$ or higher than $95 \%$ overall response inhibition (collapsed across SSD) in the stop conditions. Recognition data for the remaining 19 participants were analyzed first to ensure that they had complied with the memory instructions. All contrasts used the mean square error of the relevant main effect or interaction.

\section{Recognition Accuracy}

The percentage of yes responses was analyzed as a function of word type ( $R, F$, foil) in a one-way repeated measures ANOVA. This analysis indicated a significant effect of word type $\left[F(2,36)=59.83, M S_{\mathrm{e}}=113.29, p<.01\right]$. Planned contrasts revealed significantly more yes responses to R words $(M=57.5 \%, S E=4.4 \%)$ than to $\mathrm{F}$ words $(M=$ $44.3 \%, S E=4.5 \%)[F(1,36)=14.65, p<.01]$ and more yes responses to $\mathrm{F}$ words $(M=44.3 \%, S E=4.5 \%)$ than to unstudied foil words $(M=20.3 \%, S E=4.7 \%)[F(1,36)=$ $48.45, p<.01]$. These findings demonstrate a directed forgetting effect $(\mathrm{R}-\mathrm{F}=13.2 \%)$, verifying that participants used the memory instructions as intended.

\section{Go Trials}

Go-trial RTs. Mean RTs were calculated for go trials on which a detection response was executed within the interval between go-signal onset and trial end. A withinsubjects ANOVA revealed a significant effect of memory instruction $\left[F(1,18)=20.20, M S_{\mathrm{e}}=2,272.90, p<.01\right]$ : RTs were longer when the go signal followed $F$ instruc- 

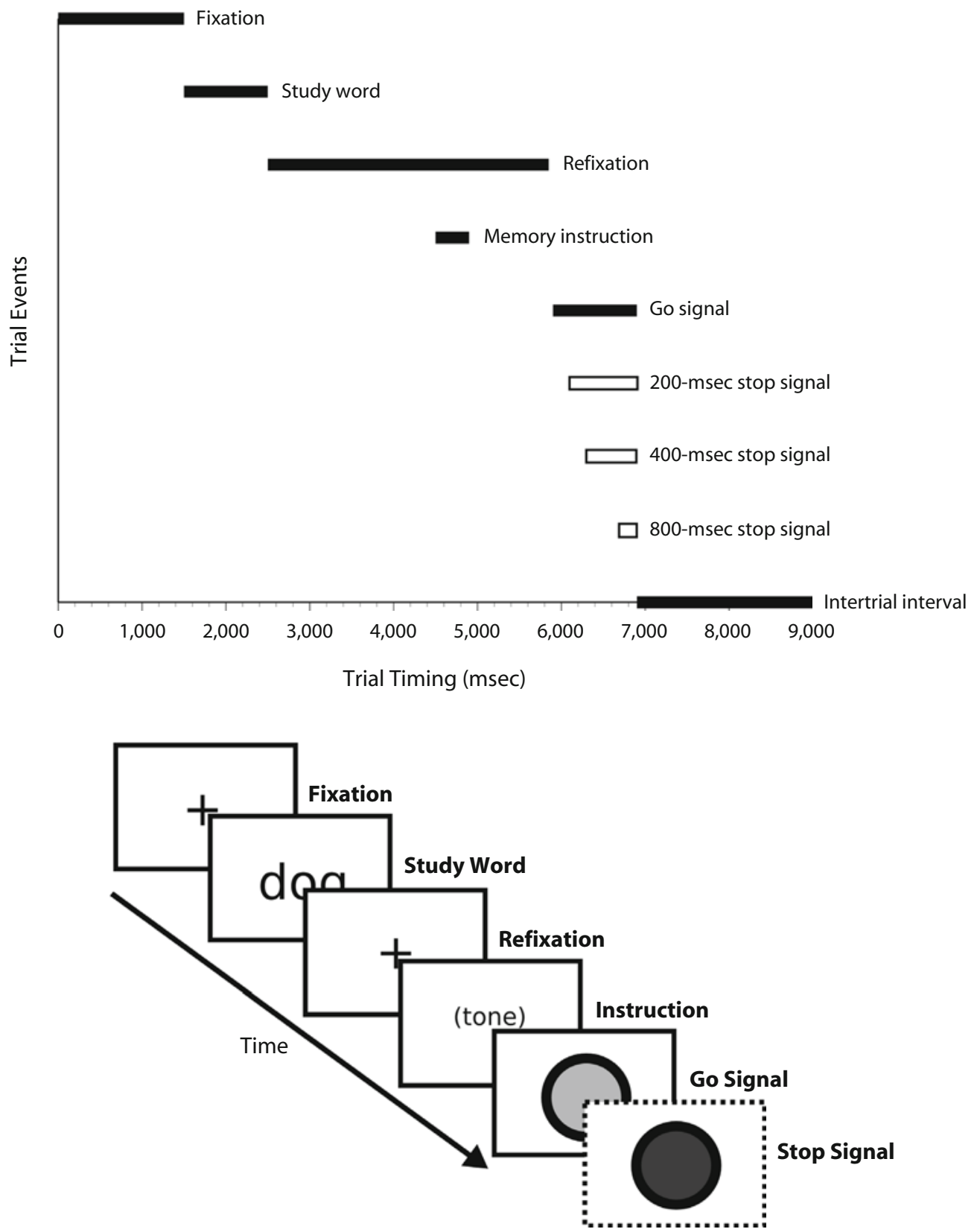

Figure 1. (Top) Timing of trial events for Experiment 1. The hollow bars represent stop signals. Only one stop-signal event was presented during any given stop trial; no stop signals were present during go trials. (Bottom) Schematic of a study-phase trial.

tions $(M=730 \mathrm{msec}, S E=29)$ than when it followed R instructions $(M=661 \mathrm{msec}, S E=31)$.

Errors. A trial was considered an error if a detection response was executed prior to go-signal onset or not at all in the interval between go-signal onset and the end of trial. An equivalent ANOVA performed on the percentage of errors for go trials revealed no differences between $\mathrm{R}(M=6.1 \%$, $S E=1.6 \%)$ and $\mathrm{F}(M=5.4 \%, S E=1.0 \%)$ trials $(F<1)$.

\section{Stop Trials}

Response inhibition. The probability of successfully inhibiting a response during the stop trials is shown in
Figure 2. These data were analyzed using a 2 (memory instruction: R, F) $\times 3$ (SSD: $200,400,800 \mathrm{msec}$ ) withinsubjects ANOVA. The main effect of memory instruction revealed that participants were significantly more likely to inhibit their response following $\mathrm{F}$ instructions than following $\mathrm{R}$ instructions $\left[F(1,18)=9.90, M S_{\mathrm{e}}=201.45\right.$, $p<.01]$. The probability of successfully inhibiting a response also decreased as a function of increasing SSD $\left[F(2,36)=117.59, M S_{\mathrm{e}}=383.09, p<.01\right]$. These findings were qualified by a significant memory instruction $X$ SSD interaction $\left[F(2,36)=3.88, M S_{\mathrm{e}}=74.37, p<.03\right]$. Participants exhibited greater response inhibition follow- 


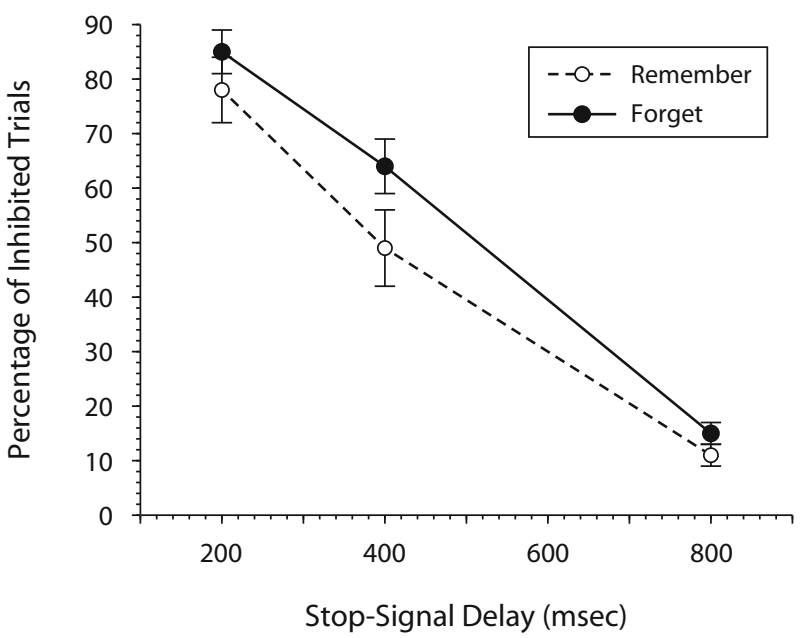

Figure 2. Mean percentage of inhibited trials in Experiment 1 as a function of memory instruction (remember, forget) and stopsignal delay $(200,400$, and $800 \mathrm{msec})$; error bars represent one standard error of the mean.

ing $\mathrm{F}$ instructions than following $\mathrm{R}$ instructions at SSDs of $200 \mathrm{msec}[F(1,36)=5.36, p<.03]$ and $400 \mathrm{msec}$ $[F(1,36)=27.14, p<.01]$, but not at $800-\mathrm{msec}$ SSDs $[F(1,36)=2.09, p>.15]$.

Signal-respond RTs. The RTs for stop trials in which a response was erroneous were collapsed across SSD and were analyzed as a function of memory instruction. Although RTs tended to be longer for F trials $(M=624 \mathrm{msec}$, $S E=27)$ than for R trials $(M=595 \mathrm{msec}, S E=28)$, this difference failed to reach significance $[F(1,18)=2.72$, $\left.M S_{\mathrm{e}}=2,867.15, p=.12\right]$.

Stop-signal RTs. Following the procedure described by Logan (1994), SSRTs were calculated on a participantby-participant basis by (1) organizing the (R or F) go-trial RTs into ascending order, so as to create a distribution of RTs, (2) selecting the $n$th RT, where $n$ was calculated by multiplying the total number of values in this distribution by the probability of incorrectly responding at a given SSD (this process was repeated for each SSD), (3) subtracting the appropriate SSD from each RT value, and (4) averaging together the SSRTs calculated for each SSD. This process was conducted separately for $\mathrm{R}$ and $\mathrm{F}$ trials, resulting in separate SSRTs for each condition. Although SSRTs were shorter for F trials $(M=212 \mathrm{msec}, S E=18)$ than for R trials $(M=240 \mathrm{msec}, S E=32)$, this difference failed to approach significance $(F<1)$.

\section{Discussion}

Experiment 1 determined whether the cessation of rehearsal following an $\mathrm{F}$ instruction engages mechanisms similar to those involved in the inhibition of an overt motor response (see Hourihan \& Taylor, 2006). Although the gosignal RTs were longer than generally expected for a simple detection task, this did not appear to be due to participants "waiting" to determine whether a stop signal would be presented: A waiting strategy would have resulted in a relatively flat inhibition function, with perfect or nearly perfect inhibition across all SSDs (see Logan, 1994); far from showing such a pattern, when averaged across $\mathrm{R}$ and F trials, the present data exhibited an $81 \%, 57 \%$, and $13 \%$ mean probability of stopping at the 200-, 400-, and 800 msec SSDs, respectively. Furthermore, participants were expected to be slower than is typical of a detection response, because they were engaged in a complicated memory task concurrent with the demanding secondary stop-signal task. The distribution of limited-capacity processing resources between these tasks can account for the relatively slow RTs (see, e.g., Posner \& Boies, 1971).

Participants were more successful at stopping following $\mathrm{F}$ instructions than following $\mathrm{R}$ instructions; however, gosignal RTs were also longer following $\mathrm{F}$ instructions than following R instructions (see Fawcett \& Taylor, 2008). As a result, better stopping performance following $\mathrm{F}$ instructions was associated with an increase in F-trial go-signal RTs rather than a decrease in F-trial SSRTs: Instantiating the F instructions slowed the go process in such a way that the stop process "won" more races; it did not speed the stop process. Because go-signal RTs provided an index of cognitive load (see Kahneman, 1973), slower go-signal RTs on $\mathrm{F}$ trials than on $\mathrm{R}$ trials provide converging evidence that the mechanism responsible for instantiating an $\mathrm{F}$ instruction is cognitively demanding and cannot be attributed to passive decay of the F-item representation (Fawcett \& Taylor, 2008). Nevertheless, the lack of a concomitant effect on SSRTs argues that the active cognitive mechanism that is engaged to prevent the commitment of an F word to memory is not the same as that which is engaged to prevent the execution of an overt response; any similarity between the two processes (see Hourihan \& Taylor, 2006) is purely analogous.

To further explore these findings, Experiment 2 replicated and extended the paradigm developed in Experiment 1.

\section{EXPERIMENT 2}

Experiment 2 made four major changes to the study phase: (1) Words were presented with equal probability to either the left or the right of center, (2) the target was presented with equal probability to either the left or the right of center, (3) participants were required to localize instead of detect the target, and (4) the stop signal was a change in the color fill of the central fixation circle. Presenting the study words and localization targets to the left and right enabled us to explore item-method directed forgetting and stop-signal inhibition within the context of a paradigm that would also allow us to examine IOR (Posner \& Cohen, 1984).

One claim of the attentional inhibition hypothesis (see, e.g., Zacks et al., 1996) is that attention is actively withdrawn from the representation of the $\mathrm{F}$ word in working memory (which includes information about its spatial location; see Hourihan, Goldberg, \& Taylor, 2007). The IOR effect can be used to test this characterization, because the effect is typically revealed only when attention has been removed from the peripheral location of a sudden onset cue. If attention is not removed from the cued location, a facilitatory effect is produced that can mask the IOR 
effect (Collie, Maruff, Yucel, Danckert, \& Currie, 2000; Danziger \& Kingstone, 1999; Pratt, Hillis, \& Gold, 2001). Thus, to the extent that an $\mathrm{F}$ instruction engages an active and more complete withdrawal of attention, IOR should be of larger magnitude for a target that follows a peripherally presented $\mathrm{F}$ word than for a target that follows a peripherally presented $\mathrm{R}$ word.

Using this rationale, Taylor (2005) presented study words to the left or right of center. These acted as spatially uninformative cues for a subsequent target requiring a localization response; between study-word onset and target onset, an auditory tone instructed participants to remember or forget the preceding word. As predicted, the magnitude of the IOR effect was larger following $\mathrm{F}$ instructions than following R instructions. Studies from our lab have shown that larger IOR on $\mathrm{F}$ trials than on $\mathrm{R}$ trials is related to a relative increase in the magnitude of IOR following F instructions, compared with an otherwise identical nomemory control condition (e.g., Taylor, 2005).

Importantly, Ivanoff and Taylor (2006) have shown that the IOR effect also influences stopping performance: The probability of successfully preventing an unwanted motor response to a target is greater when the target appears in a cued (vs. an uncued) location. However, SSRTs are unaffected by cuing condition, suggesting that differences in stopping performance could be accounted for by differences in go-signal RTs.

Given that IOR interacts with item-method directed forgetting (Taylor, 2005) and improves stopping (Ivanoff $\&$ Taylor, 2006) and that item-method directed forgetting also improves stopping (Experiment 1), these tasks should interact when tested together in a single paradigm. Experiment 2 tested this notion by integrating an orienting task into the study phase of the paradigm developed in Experiment 1 . During the study phase, words were presented peripherally (to the left or right) to act as uninformative cues for a subsequent localization target that could be presented in the same location as the study word (cued) or in the opposite location (uncued). The onset of the target in the visual periphery served as the go signal; a color change in a central fixation stimulus served as a stop signal.

The predictions for Experiment 2 were as follows: (1) Responses should be slower following $F$ instructions than following R instructions (Fawcett \& Taylor, 2008), (2) a larger IOR effect should be observed following $\mathrm{F}$ instructions than following R instructions (Taylor, 2005), (3) better stopping should be observed for cued F trials than for uncued $\mathrm{F}$ trials (because $\mathrm{F}$ trials are subject to more reliable IOR effects than are R trials; Ivanoff \& Taylor, 2006; Taylor, 2005), and (4) better stopping should be observed following $\mathrm{F}$ instructions than following $\mathrm{R}$ instructions (see Experiment 1). Neither memory instruction nor cuing condition was expected to affect SSRT (Ivanoff \& Taylor, 2006); instead, any interactions were expected to occur in the speed to execute responses on go trials.

\section{Method}

\section{Participants}

Fifty-two undergraduate students enrolled at Dalhousie University participated for course credit.

\section{Stimuli and Apparatus}

The stimuli and apparatus were identical to those in Experiment 1, with the following exceptions. During the study phase, three boxes were presented, each with a 2-point black border and measuring $4.5^{\circ}$ of visual angle (150 pixels) on all sides. The boxes were vertically centered and were positioned horizontally, so that the middle box was centered on the computer screen, and the center of each box was separated by $7.5^{\circ}$ of visual angle. The fixation stimulus consisted of a yellow-filled circle, outlined in a 4-point black border, $1.5^{\circ}$ of visual angle in diameter. On stop trials, the fixation stimulus changed from yellow to red filled. The target was an asterisk printed in Helvetica 56-point font that appeared in either the left or the right box.

A new list of 384 lowercase nouns was randomly selected by the Paivio, Yuille, and Madigan Word List Generator (www.math .yorku.ca/SCS/Online/paivio/). These words had an average KučeraFrancis word frequency of 53.05, an imagery rating of 5.77, and a concreteness rating of 6.03 . The words were $3-8$ letters in length, with a mean of 5.54 letters and 1.68 syllables. Custom software was used to randomly divide the master word list into $\mathrm{F}(n=96), \mathrm{R}(n=$ $96)$, and foil $(n=192)$ word lists, resulting in a unique list composition for each participant.

\section{Procedure}

The procedure was the same as that in Experiment 1, except for the following. Pursuant to the change from a detection task to a localization task, participants were now instructed that (1) on each trial, a word would be presented in either the left or the right box; (2) this word would be followed by a target (the asterisk) presented in either the left or the right box and would require a speeded localization response; (3) following this asterisk on some trials, the central yellow-filled circle would change into a red-filled circle (stop signal) after a variable delay; and (4) when possible, they should withhold responses for any trials in which this change from yellow to red occurred. Instructions indicated that the location of the study word was not predictive of the subsequent target location.

Practice phase. As in Experiment 1, practice continued until the experimenter felt that the participant understood the task.

Familiarization phase. The familiarization phase was identical to that in Experiment 1.

Study phase. At the start of the study phase, three boxes were arranged from left to right and remained on the screen. As depicted in Figure 3, each trial began with the presentation of a fixation stimulus (yellow-filled circle) in the center box, which remained visible throughout that trial. After an 800 -msec delay, a word was presented in the center of either the right or the left box for $600 \mathrm{msec}$. The word was drawn randomly, without replacement, from the $\mathrm{R}$ or F word list. At $100 \mathrm{msec}$ following the study word, the corresponding ( $\mathrm{R}$ or $\mathrm{F}$ ) memory instruction (high or low tone) was presented for $400 \mathrm{msec}$. An asterisk (go signal) $600 \mathrm{msec}$ in duration was presented $500 \mathrm{msec}$ following the onset of the memory instruction. Thus, the instruction-go-signal SOA was $500 \mathrm{msec}$, and the wordgo-signal SOA was $1,200 \mathrm{msec}$. This particular word-go-signal SOA $(1,200 \mathrm{msec})$ was chosen because it is known to produce a measurable IOR effect (see Samuel \& Kat, 2003; Taylor, 2005). After the asterisk on each trial, the yellow-filled circle at center changed with equal probability at one of three SSDs: 200,400 , or $800 \mathrm{msec}$ (see Ivanoff \& Taylor, 2006). On a random half of the trials (stop trials), the circle changed from yellow to red filled; on the remaining trials (go trials), the yellow-filled circle was removed and then restored (i.e., replaced with an identical stimulus) with equal probability at timings of 200,400 , or $800 \mathrm{msec}$ following go-signal onset. Although the change on go trials was not noticeable to the participants, even undetectable visual transients can attract attention (see, e.g., McCormick, 1997); as such, this change was included to control for any effects on attention that might occur as a result of the change in the central fixation circle on stop trials (other than the change of color per se; see Ivanoff \& Taylor, 2006). Regardless of trial type, the onset of this change lasted $400 \mathrm{msec}$ (after which the circle at center reverted to yellow filled). On go trials, participants were required to 

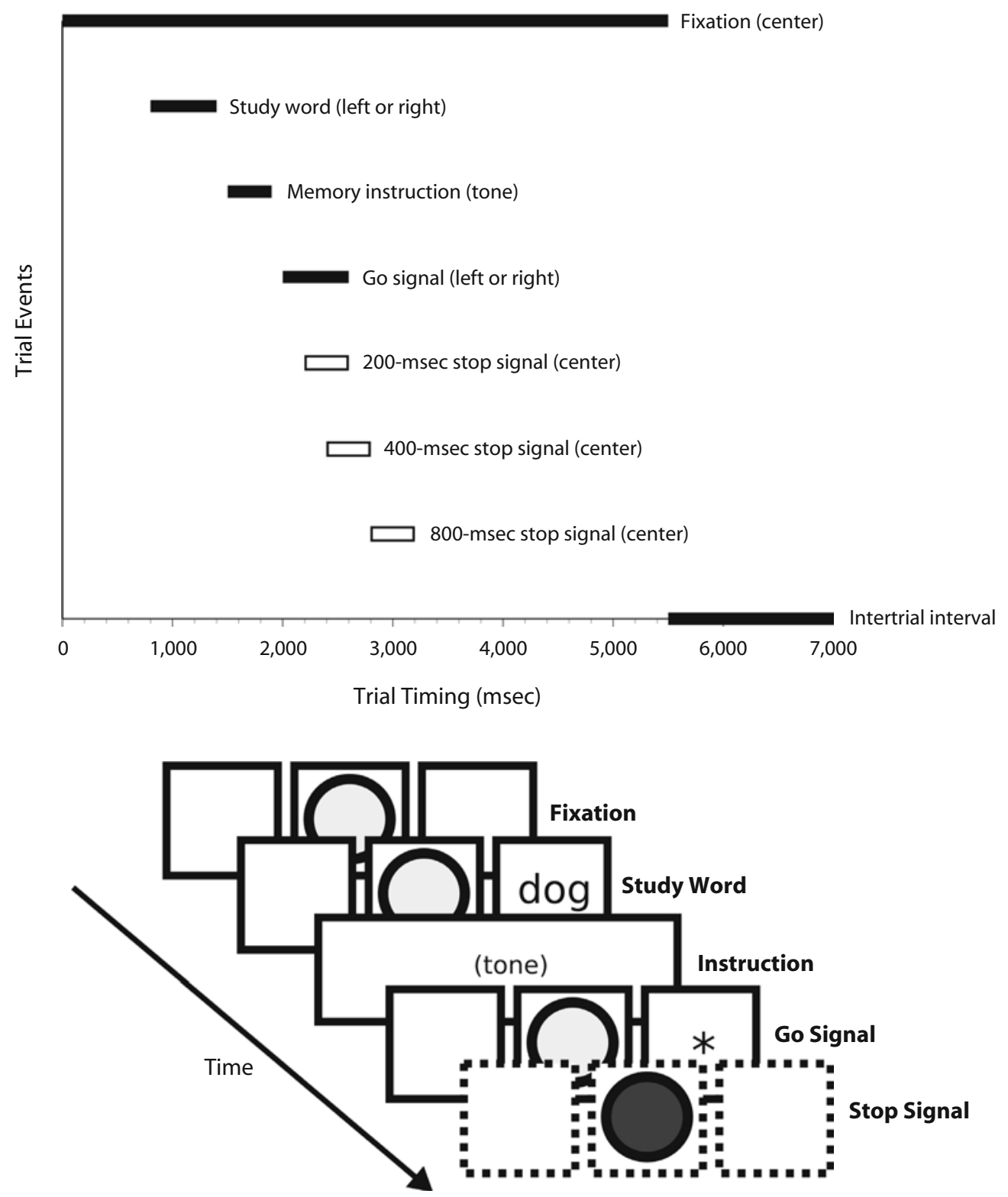

Figure 3. (Top) Timing of trial events for Experiment 2. The hollow bars represent stop signals. Only one stop-signal event was presented during any given stop trial. Visual transients (i.e., removal and replacement of the circle) similar to the stop signals were presented at the same time intervals during go trials. Event location (left, right, or center) is provided in parentheses next to each event. (Bottom) Schematic of a (cued) study-phase trial.

press the "z" key if the asterisk appeared to the left and to press the " $\mathrm{m}$ " key if the asterisk appeared to the right; on stop trials, participants were required to withhold their response. Each trial ended with an enforced intertrial interval of $1,500 \mathrm{msec}$, resulting in a total trial duration of 7,000 msec.

For the purpose of analysis, word and target location were collapsed according to whether the asterisk occurred in the same location as the word (cued: left-left, right-right) or in the opposite location (uncued: left-right, right-left). As such, the study was conceived as a 2 (target location: cued, uncued) $\times 2$ (memory instruction: R, F) $\times 2$ (trial type: stop, go) $\times 3$ (SSD: 200, 400, and $800 \mathrm{msec}$ ) factorial.

Overall, 192 study trials were presented. Trials were equally distributed across each combination of target location (cued, uncued), memory instruction (R, F), trial type (stop, go), and SSD (200, 400, and $800 \mathrm{msec}$ ), with eight replications of each cell. Four buffer trials at the beginning and the end were included to minimize recency and primacy effects.

Recognition phase. The recognition phase was the same as that described for Experiment 1, with the exception that 384 trials were presented (96 R, $96 \mathrm{~F}$, and 192 foil).

\section{Results}

The data from 4 participants were excluded as a result of more than $50 \%$ missed or incorrect target responses in one or more of the go conditions or because of stated confusion regarding the instructions. The recognition data 
Table 1

Mean Go-Trial Localization Reaction Times (RTs, in Milliseconds) and Percentage Errors (\%) in Experiment 2 As a Function of Memory Instruction and Target Location (Cued, Uncued)

\begin{tabular}{|c|c|c|c|c|c|c|c|c|c|c|}
\hline \multirow{3}{*}{$\begin{array}{l}\text { Memory } \\
\text { Instruction }\end{array}$} & \multicolumn{6}{|c|}{ Go-Trial RTs } & \multicolumn{4}{|c|}{ Go-Trial Errors } \\
\hline & \multicolumn{2}{|c|}{ Cued } & \multicolumn{2}{|c|}{ Uncued } & \multicolumn{2}{|c|}{ IOR } & \multicolumn{2}{|c|}{ Cued } & \multicolumn{2}{|c|}{ Uncued } \\
\hline & $M$ & $\overline{S E}$ & $M$ & $\overline{S E}$ & $\bar{M}$ & $\overline{S E}$ & $M$ & $\overline{S E}$ & $M$ & $S E$ \\
\hline Remember & 681 & 39 & 667 & 43 & 14 & 10 & 8.9 & 1.5 & 6.2 & 1.3 \\
\hline Forget & 764 & 40 & 714 & 40 & 50 & 10 & 11.8 & 1.5 & 8.9 & 1.5 \\
\hline
\end{tabular}

Note-IOR, inhibition of return.

for the remaining 48 participants were analyzed first to ensure that they were using the memory instructions as intended.

\section{Recognition Accuracy}

The percentage of yes responses was analyzed as a function of word type (R, F, foil) using a one-way repeated measures ANOVA. This analysis revealed a significant main effect $\left[F(2,94)=115.28, M S_{\mathrm{e}}=122.56, p<\right.$ $.01]$, with more yes responses for R words $(M=54.2 \%$, $S E=2.4 \%)$ than for F words $(M=38.3 \%, S E=2.4 \%)$ $[F(1,94)=49.84, p<.01]$ and more for $\mathrm{F}$ words $(M=$ $38.3 \%, S E=2.4 \%)$ than for unstudied foil words ( $M=$ $16.5 \%, S E=2.1 \%)[F(1,94)=65.81, p<.01]$. These findings once again demonstrate a directed forgetting effect $(\mathrm{R}-\mathrm{F}=15.9 \%)$, verifying that participants used the memory instructions as intended.

\section{Go Trials}

Go-trial RTs. Mean RTs were calculated for go trials on which a correct localization response was executed within 1,500 msec of go-signal onset. During go trials, the yellow-filled circle was removed and replaced at delays of 200,400 , or $800 \mathrm{msec}$ relative to target onset (see above). Although this change was undetectable, an initial analysis of go-trial RTs included signal delay as a factor to determine whether its presence affected the go task. Because the main effect of signal delay failed to reach significance and did not significantly interact with any other variables (all $p \mathrm{~s}>.13$ ), subsequent analyses of go-trial RTs were collapsed over SSD. Go trials were thus analyzed as a function of memory instruction $(\mathrm{R}, \mathrm{F})$ and target location (cued, uncued).

Replicating the findings of Experiment 1, this analysis revealed a significant effect of memory instruction $\left[F(1,47)=44.08, M S_{\mathrm{e}}=4,617.96, p<.01\right]$, indicating longer RTs when the go signal followed $\mathrm{F}$ instructions $(M=739 \mathrm{msec}, S E=28)$ than when it followed $\mathrm{R}$ instructions $(M=674 \mathrm{msec}, S E=29)$. There was also a significant 33-msec IOR effect [target location, $F(1,47)=$ $\left.20.18, M S_{\mathrm{e}}=2,517.57, p<.01\right]$ : RTs were longer to targets that appeared in the same location as the study word (cued, $M=723 \mathrm{msec}, S E=28$ ) than they were to targets that appeared in a different location from the study word (uncued, $M=690 \mathrm{msec}, S E=29$ ). These findings were qualified by a significant memory instruction $\times$ target location interaction $\left[F(1,47)=7.39, M S_{\mathrm{e}}=2,060.10\right.$, $p<.01]$. Replicating the work of Taylor (2005), a signifi- cant 50-msec IOR effect was observed for targets that followed peripherally presented $\mathrm{F}$ words $[F(1,47)=29.52$, $p<.01]$, but a nonsignificant $14-\mathrm{msec}$ IOR effect was observed for targets that followed peripherally presented $\mathrm{R}$ words $[F(1,47)=2.53, p>.11]$. These data are presented in Table 1.

Errors. An equivalent ANOVA performed on the percentage of errors (i.e., misses and incorrect localization responses; see Table 1) for go trials revealed main effects of memory instruction $\left[F(1,47)=16.62, M S_{\mathrm{e}}=22.99\right.$, $p<.01]$ and target location $\left[F(1,47)=16.62, M S_{\mathrm{e}}=\right.$ $22.99, p<.01]$. Participants made fewer errors for $\mathrm{R}$ trials $(M=7.5 \%, S E=1.1 \%)$ than for F trials $(M=10.3 \%$, $S E=1.0 \%)$ and fewer errors for uncued trials $(M=7.5 \%$, $S E=1.1 \%)$ than for cued trials $(M=10.3 \%, S E=1.0 \%)$. Importantly, the target location $X$ instruction interaction failed to approach significance $(F<1)$.

\section{Stop Trials}

Response inhibition. The probability of successfully inhibiting a response for each stop-trial condition is shown in Figure 4. These data were analyzed using a 2 (memory instruction: R, F) $\times 2$ (target location: cued, uncued) $\times 3$ (SSD: 200, 400, and $800 \mathrm{msec}$ ) withinsubjects ANOVA. There was a significant main effect of target location $\left[F(1,47)=5.24, M S_{\mathrm{e}}=124.39, p<.03\right]$,

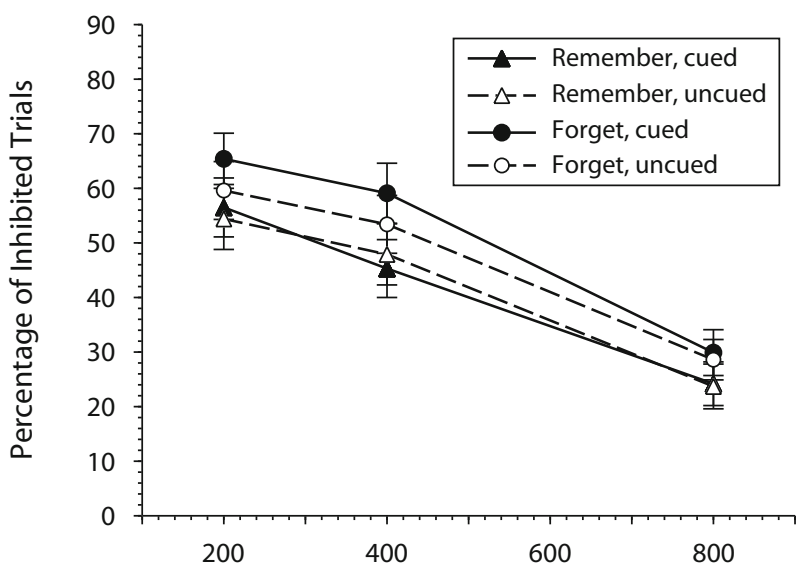

Stop-Signal Delay (msec)

Figure 4. Mean percentage of inhibited trials in Experiment 2 as a function of memory instruction (remember, forget), target location (cued, uncued), and stop-signal delay $(200,400$, and $800 \mathrm{msec}$ ); error bars represent one standard error of the mean. 
indicating that participants were more likely to inhibit their response when the target appeared in the same location as the peripherally presented study word (cued, $M=$ $46.7 \%, S E=2.2 \%$ ) than when it appeared in a different location (uncued, $M=44.6 \%, S E=2.2 \%$ ). Consistent with Experiment 1, the probability of successfully inhibiting a response decreased with increasing $\operatorname{SSD}[F(2,94)=$ $\left.76.74, M S_{\mathrm{e}}=716.90, p<.01\right]$. Finally, a significant main effect of memory instruction $\left[F(1,47)=22.77, M S_{\mathrm{e}}=\right.$ $340.20, p<.01]$ indicated greater response inhibition for F trials $(M=49.3 \%, S E=2.1 \%)$ than for R trials $(M=$ $42.0 \%, S E=2.2 \%$ ). Unlike in Experiment 1, the memory instruction $\times \mathrm{SSD}$ interaction failed to reach significance $\left[F(2,94)=1.83, M S_{\mathrm{e}}=122.93, p>.16\right]$. Stopping was better following $\mathrm{F}$ instructions than following $\mathrm{R}$ instructions at all three SSDs: $200 \mathrm{msec}[F(1,94)=19.30, p<$ $.01], 400 \mathrm{msec}[F(1,94)=36.25, p<.01]$, and $800 \mathrm{msec}$ $[F(1,94)=11.13, p<.01]$.

Critically, the memory instruction $\times$ target location interaction was significant $\left[F(1,47)=4.31, M S_{\mathrm{e}}=150.98\right.$, $p<.05$ ]; planned contrasts were conducted comparing cued and uncued conditions separately for $\mathrm{R}$ and $\mathrm{F}$ trials to determine whether the effects of IOR on stop-signal inhibition were affected by the removal of attention that was hypothesized to occur following an $\mathrm{F}$ instruction. Response inhibition was greater for cued $\mathrm{F}$ trials $(M=$ $51.5 \%, S E=3.1 \%)$ than for uncued F trials $(M=47.2 \%$, $S E=3.0 \%)[F(1,47)=8.62, p<.01]$. Response inhibition results for cued R trials $(M=42.0 \%, S E=3.1 \%)$ and uncued R trials $(M=42.0 \%, S E=3.1 \%)$ were statistically and numerically equivalent $(F<1)$. No other effects or interactions reached significance (all $p \mathrm{~s}>.20$ ).

Signal-respond RTs. The RTs for stop trials in which a response was erroneous were collapsed across SSD and analyzed as a function of memory instruction $(\mathrm{R}, \mathrm{F})$ and target location (cued, uncued). This analysis required data for each combination of memory instruction and target location; this requirement was met in the data contributed by 44 participants. Localization RTs were longer for F trials $(M=582 \mathrm{msec}, S E=21)$ than for R trials $(M=$ $521 \mathrm{msec}, S E=18)\left[F(1,43)=39.73, M S_{\mathrm{e}}=4,089.23\right.$, $p<.01]$. Furthermore, the main effect of target location $\left[F(1,43)=13.29, M S_{\mathrm{e}}=4,169.49, p<.01\right]$ indicated longer RTs for cued trials $(M=569 \mathrm{msec}, S E=20)$ than for uncued trials $(M=534 \mathrm{msec}, S E=19)$, resulting in a significant $35-\mathrm{msec}$ IOR effect. These effects were qualified by a significant memory instruction $\times$ target location interaction $\left[F(1,43)=7.53, M S_{\mathrm{e}}=4,087.25\right.$, $p<.01]$. Similar to the go-trial RT data presented above, planned contrasts confirmed longer RTs for cued $\mathrm{F}$ trials $(M=613 \mathrm{msec}, S E=30)$ than for uncued F trials $(M=$ $551 \mathrm{msec}, S E=29)$, revealing a significant 62 -msec IOR effect $[F(1,43)=20.64, p<.01]$; localization RTs were statistically equivalent for cued R trials $(M=526 \mathrm{msec}$, $S E=24)$ and uncued R trials $(M=517 \mathrm{msec}, S E=26)$, revealing a nonsignificant 9 -msec IOR effect $(F<1)$.

SSRTs. SSRTs were calculated separately for each combination of memory instruction (R, F) and target location (cued, uncued), following the procedure described by Logan (1994); these data are presented in Table 2.
Table 2

Mean Stop-Trial Stop-Signal Reaction Times (in Milliseconds) in Experiment 2 As a Function of Memory Instruction and Target Location

\begin{tabular}{|c|c|c|c|c|}
\hline \multirow{3}{*}{$\begin{array}{l}\text { Memory } \\
\text { Instruction }\end{array}$} & \multicolumn{4}{|c|}{ Target Location } \\
\hline & \multicolumn{2}{|c|}{ Cued } & \multicolumn{2}{|c|}{ Uncued } \\
\hline & $M$ & $S E$ & $M$ & $S E$ \\
\hline Remember & 217 & 22 & 198 & 22 \\
\hline Forget & 218 & 21 & 204 & 24 \\
\hline
\end{tabular}

No main effects or interactions reached significance (all $p \mathrm{~s}>.30)$.

\section{Discussion}

Experiment 2 integrated an orienting component into the study-phase stop-signal task developed in Experiment 1. Study words were presented to the left or right of center to act as uninformative cues for a localization target presented in the same location as the study word (cued) or in the opposite location (uncued). As predicted, participants were once again more successful at stopping following $\mathrm{F}$ instructions than following $\mathrm{R}$ instructions and exhibited slower F-trial (relative to R-trial) go-signal RTs. A significant IOR effect was observed following $\mathrm{F}$ instructions but not following $\mathrm{R}$ instructions (see Taylor, 2005).

To determine whether the $F>\mathrm{R}$ IOR difference was likely due to a relative increase in IOR following an $\mathrm{F}$ instruction and/or a relative decrease in IOR following an $\mathrm{R}$ instruction, we collected data from 21 new participants in a no-memory control condition. The exact methods used in the study phase of Experiment 2 were repeated, except that the peripherally presented words served only as unpredictive spatial cues, and the (high or low) tones following each word were meaningless: No words needed to be committed to memory, and no memory test was administered. Even though we included stop trials in this control experiment (to ensure that the memory component was the only thing that changed from the study trials of Experiment 2), the sole interest was in determining the baseline magnitude of IOR on go trials. Mean go-trial RTs were calculated for trials on which a correct localization response was executed within 1,500 $\mathrm{msec}$ of target onset. Go-trial RTs were analyzed as a function of the task-irrelevant tone (high, low), signal delay (200, 400, and $800 \mathrm{msec}$ ), and target location (cued, uncued), using a repeated measures ANOVA. Critically, only the main effect of target location reached significance $[F(1,20)=$ $4.95, M S_{\mathrm{e}}=3,811.21, p<.04$; all other $\left.p \mathrm{~s}>.08\right]$. With a mean RT of $801 \mathrm{msec}(S E=46)$ to cued targets and of $784 \mathrm{msec}(S E=45)$ to uncued targets, a significant 17-msec IOR effect was observed. An equivalent ANOVA performed on the percentage of errors (i.e., misses and incorrect localization responses) during go trials revealed no significant effects or interactions (all $p \mathrm{~s}>.12$ ).

Importantly, the $17-\mathrm{msec}(S E=10)$ IOR effect obtained in the no-memory control condition was significantly smaller than the 50 -msec $(S E=10)$ IOR effect observed following $\mathrm{F}$ instructions $\left[F(1,67)=4.34, M S_{\mathrm{e}}=\right.$ $1,828.14, p<.05]$ but did not statistically differ from the 
14 -msec $(S E=10)$ IOR effect observed following $\mathrm{R}$ instructions $\left[F(1,67)=0.03, M S_{\mathrm{e}}=2,013.50, p>\right.$.87]. Although these findings should be interpreted cautiously because of the between-subjects nature of the comparisons, they suggest that the $F>\mathrm{R}$ IOR difference observed in Experiment 2 was likely due - primarily, if not exclusively - to the relative magnification of IOR by the $\mathrm{F}$ instructions (as opposed to a relative reduction of IOR by the $\mathrm{R}$ instructions).

To determine whether the magnitude of the $\mathrm{F}>\mathrm{R}$ gosignal RT difference on study trials was related to subsequent recognition performance, $\mathrm{F}$ and $\mathrm{R}$ go-signal RTs were analyzed separately as a function of outcome on the subsequent recognition test (remembered vs. forgotten; see Fawcett \& Taylor, 2008) and target location. If F-trial go-signal RTs reflect increased cognitive demands associated with intentionally forgetting the study word, responses should have been slower for $\mathrm{F}$ trials on which the study word was subsequently forgotten $\left(\mathrm{F}_{\text {forgotten }}\right)$ than for $\mathrm{F}$ trials on which the study word was subsequently remembered $\left(\mathrm{F}_{\text {remembered }}\right)$. No differences were predicted for $\mathrm{R}$ trials. This analysis required data for each combination of memory instruction, target location, and recognition outcome; this requirement was met in the data contributed by 37 participants. For F trials, the main effect of target location reflected a significant 49 -msec IOR effect $\left[F(1,36)=18.01, M S_{\mathrm{e}}=4,925.12, p<.01\right]$, and the main effect of recognition outcome $[F(1,36)=9.96$, $\left.M S_{\mathrm{e}}=10,076.60, p<.01\right]$ reflected significantly slower go-signal RTs for $\mathrm{F}_{\text {forgotten }}$ trials $(M=772 \mathrm{msec}, S E=$ 33) than for $\mathrm{F}_{\text {remembered }}$ trials $(M=720 \mathrm{msec}, S E=30$; see Fawcett \& Taylor, 2008). Importantly, the recognition outcome $\times$ target location interaction was significant $\left[F(1,36)=5.38, M S_{\mathrm{e}}=4,861.38, p<.03\right]$ : A significant 75 -msec IOR effect was observed for $\mathrm{F}_{\text {forgotten }}$ trials $[F(1,36)=21.73, p<.01]$, but a nonsignificant $23-\mathrm{msec}$ IOR effect was observed for $\mathrm{F}_{\text {remembered }}$ trials $[F(1,36)=$ $1.90, p>.17]$. No main effects or interactions were observed for the analogous R-trial analysis (all $p \mathrm{~s}>.27$ ). According to the outcome of this analysis, responding is slowed following the presentation of $\mathrm{F}$ items that are later successfully forgotten versus following the presentation of those $\mathrm{F}$ items that are not later forgotten.

\section{GENERAL DISCUSSION}

Two experiments were presented using a variant of the item-method directed forgetting paradigm to explore interactions between item-method directed forgetting, stop-signal inhibition, and IOR. To investigate these interactions, a secondary RT task was integrated into the study phase of each paradigm (see, e.g., Fawcett \& Taylor, 2008): Experiment 1 embedded a stop-signal task requiring a simple detection response (which was sometimes countermanded) following the memory instruction on each study-phase trial of an item-method directed forgetting task; Experiment 2 further developed this paradigm by presenting targets and study words in the left or right visual periphery and requiring a speeded localization response to targets.
In both experiments, the likelihood of successfully inhibiting an overt response was greater following $\mathrm{F}$ instructions than following $\mathrm{R}$ instructions; however, this difference was associated with a pattern of slower F-trial go-signal than R-trial go-signal RTs, rather than with differences in SSRTs. Experiment 2 revealed that the likelihood of successfully inhibiting an overt response was greater for cued trials than for uncued trials, but only following $\mathrm{F}$ instructions (when there was a corresponding go-trial RT difference). These findings are consistent with the view that intentional forgetting in this paradigm is an active cognitive process involving attentional withdrawal rather than the engagement of (covert) response inhibition. Any relation between preventing an unwanted overt response and preventing the unwanted commitment of items to memory is based on analogy rather than identity (see Hourihan \& Taylor, 2006).

Because go-signal RTs provide an index of cognitive load (see Kahneman, 1973), slower go-signal RTs following $\mathrm{F}$ instructions (relative to following $\mathrm{R}$ instructions) suggest that the instantiation of an $\mathrm{F}$ instruction is not only cognitively demanding, but also more cognitively demanding than the instantiation of an $\mathrm{R}$ instruction (see Fawcett \& Taylor, 2008). These findings are incongruent with the view that directed forgetting is accomplished by the elaborative rehearsal of $\mathrm{R}$ items and the passive decay of $\mathrm{F}$ items (see, e.g., Basden, Basden, \& Gargano, 1993): Such an interpretation of the selective rehearsal account would predict longer go-signal RTs for R trials than for F trials. An active view of forgetting such as Zacks et al.'s (1996) attentional inhibition hypothesis is supported instead - at least to the extent that it posits the active withdrawal of attention from $\mathrm{F}$ items at encoding. According to the attentional inhibition hypothesis, the instantiation of an $\mathrm{F}$ instruction leads to attentional withdrawal from the $\mathrm{F}$ item. This purges the $\mathrm{F}$ word from working memory, effectively discouraging further rehearsal and freeing processing resources for other tasks (see Roediger \& Crowder, 1972).

Our interpretation of the present $\mathrm{F}>\mathrm{R}$ difference in RTs is informed by Fawcett and Taylor (2008, Experiment 2), who presented participants with an item-method directed forgetting task that required speeded detection responses to postinstruction probes. On a random half of the trials within a block, a word was presented, followed by an $\mathrm{R}$ or $\mathrm{F}$ instruction. On the remaining trials, a string of Xs was presented instead of a word; this made the R and $\mathrm{F}$ instructions task irrelevant for that trial. Averaged over instruction-probe SOA, postinstruction-probe RTs were $494 \mathrm{msec}$ when a word was followed by an R instruction and a numerically identical $494 \mathrm{msec}$ when no word was presented (i.e., when a task-irrelevant memory instruction followed a string of Xs). In contrast, probe RTs were $516 \mathrm{msec}$ when a word was followed by an F instruction. This pattern of results suggests that $F>R$ differences in postinstruction-probe RTs are likely due to a relative increase in RT following an F instruction, as opposed to a relative decrease in RT following an R instruction.

The pattern of longer RTs following F instructions than following R instructions may tempt one to "rescue" the 
passive-decay interpretation by assuming that $\mathrm{F}$ words are passively dropped from the rehearsal set and are replaced by the active retrieval and cumulative rehearsal of previously presented $\mathrm{R}$ words. According to this argument, it is the effortful search for previous $\mathrm{R}$ words on $\mathrm{F}$ trials - and not the act of forgetting per se - that is responsible for the relative increase in post-F probe RTs. Fawcett and Taylor (2008) countered this argument on the grounds that effortful search and cumulative rehearsal of preceding $\mathrm{R}$ words would have been expected in their randomly presented noword control condition (when an X string was presented on random trials within the context of an ongoing memory task). Yet they found that RTs were faster on no-word control trials than on F-instructed word trials (see above). In the context of the present study, effortful search and rehearsal of preceding $\mathrm{R}$ words on $\mathrm{F}$ trials cannot account for the memory instruction $\times$ target location interaction that occurred within the RT data. Even allowing for the assumption that effortful retrieval of previous $\mathrm{R}$ words occurs only following $\mathrm{F}$ (but not $\mathrm{R}$ ) instructions, there is no a priori reason to expect that such a retrieval of preceding $\mathrm{R}$ words would selectively augment the removal of attention from the spatial representation of the to-be-forgotten $\mathrm{F}$ word (i.e., that retrieval of preceding $\mathrm{R}$ words would result in larger IOR on $\mathrm{F}$ trials than on $\mathrm{R}$ trials). A post hoc argument might be that searching for an $\mathrm{R}$ word to replace the $\mathrm{F}$ word requires first inhibiting the representation of the $\mathrm{F}$ item (including its spatial representation; see Hourihan et al., 2007) to prevent it from interfering with the search. Although this would account for the interaction of word location and memory instruction, it is not clear whether such a mechanism is fundamentally different from that posited by Zacks et al. (1996): Attention is actively withdrawn from the representation of an $\mathrm{F}$ item to limit its ability to interfere with the encoding of task-relevant $\mathrm{R}$ items.

Using IOR as an index of attentional removal, our findings suggest that the removal of attention was limited to (or faster or more complete on) trials in which the $\mathrm{F}$ item was successfully forgotten. From this work, it is unclear whether attention is withdrawn because the word is purged from working memory (i.e., whether attentional withdrawal is an aftereffect of forgetting) or whether the withdrawal of attention is an integral mechanism of this purge. Certainly, the attentional inhibition hypothesis (Zacks et al., 1996) would predict that forgetting is accomplished, in part, by the withdrawal of processing resources from the mental representation of the study word (including its spatial representation; Hourihan et al., 2007) upon presentation of the F instruction.

Although it is tempting to conclude that intentional forgetting and stop-signal inhibition share a common mechanism, there is little evidence to support this assertion. Neither memory instruction nor cue-target location significantly impacted SSRT in either experiment. Instead, it would appear that the effect of instruction (and cuetarget location) on stopping performance was mediated by the slowing of target responses that occurs following an $\mathrm{F}$ instruction. It is nevertheless clear that instantiating an $F$ instruction at encoding is an effortful cognitive process. This effortful process does not interact with mechanisms used to suppress unwanted overt responses but does interact with those associated with the active withdrawal of attention. This finding is instructive in light of the fact that the attention system consists of at least three isolable networks - the alerting, orienting, and executive networks (Fan, McCandliss, Sommer, Raz, \& Posner, 2002). Our findings suggest that mobilization of attention by a memory instruction is unlikely to involve a process like stop-signal inhibition (which is related to the executive attentional system) and more likely to involve the orienting attentional system (which is implicated in IOR).

\section{AUTHOR NOTE}

This research was funded by a grant from the Natural Sciences and Engineering Research Council of Canada (NSERC) to T.L.T. and an NSERC Canada Graduate Scholarship and a Killam Predoctoral Scholarship to J.M.F. We thank Carl Helmick for writing the custom software that was used to distribute words to lists. We also thank Chelsea Quinlan, Kate Thompson, Ray Klein, Aaron Newman, and Vincent LoLordo for feedback on earlier versions of the manuscript. Correspondence concerning this article should be addressed to J. M. Fawcett, Department of Psychology, Dalhousie University, 1355 Oxford Street, Halifax, NS, B3H 4J1 Canada (e-mail: jmfawcet@dal.ca).

\section{REFERENCES}

Anderson, M. C. (2003). Rethinking interference theory: Executive control and the mechanisms of forgetting. Journal of Memory \& Language, 49, 415-445.

Basden, B. H., \& Basden, D. R. (1998). Directed forgetting: A contrast of methods and interpretations. In J. M. Golding \& C. M. MacLeod (Eds.), Intentional forgetting: Interdisciplinary approaches (pp. 139172). Mahwah, NJ: Erlbaum.

Basden, B. H., Basden, D. R., \& Gargano, G. J. (1993). Directed forgetting in implicit and explicit memory tests: A comparison of methods. Journal of Experimental Psychology: Learning, Memory, \& Cognition, 19, 603-616.

BJorK, R. A. (1972). Theoretical implications of directed forgetting. In A. W. Melton \& E. Martin (Eds.), Coding processes in human memory (pp. 217-235). Washington, DC: Winston.

Cohen, J., MacWhinney, B., Flatt, M., \& Provost, J. (1993). PsyScope: An interactive graphic system for designing and controlling experiments in the psychology laboratory using Macintosh computers. Behavior Research Methods, Instruments, \& Computers, 25, $257-$ 271.

Collie, A., Maruff, P., Yucel, M., Danckert, J., \& Currie, J. (2000). Spatiotemporal distribution of facilitation and inhibition of return arising from the reflexive orienting of covert attention. Journal of Experimental Psychology: Human Perception \& Performance, 26, 1733-1745.

Danziger, S., \& Kingstone, A. (1999). Unmasking the inhibition of return phenomenon. Perception \& Psychophysics, 61, 1024-1037.

Engle, R. W., Conway, A. R. A., Tuholski, S. W., \& Shisler, R. J. (1995). A resource account of inhibition. Psychological Science, 6, $122-125$.

Fan, J., McCandliss, B. D., Sommer, T., Raz, A., \& Posner, M. I. (2002). Testing the efficiency and independence of attentional networks. Journal of Cognitive Neuroscience, 14, 340-347.

FAWCETT, J. M., \& TAYLOR, T. L. (2008). Forgetting is effortful: Evidence from reaction time probes in an item-method directed forgetting task. Memory \& Cognition, 36, 1168-1181.

Golding, J. M., Roper, K. L., \& Hauselt, J. (1996). To forget or not to forget: The effect of probability of test on directed forgetting. Quarterly Journal of Experimental Psychology, 49A, 326-340.

Greene, R. L. (1987). Effects of maintenance rehearsal on human memory. Psychological Bulletin, 102, 403-413.

HASHER, L., \& ZACKS, R. T. (1988). Working memory, comprehension, and aging: A review and a new view. In G. H. Bower (Ed.), The psychology of learning and motivation (Vol. 22, pp. 193-225). New York: Academic Press. 
Hourihan, K. L., Goldberg, S., \& TaYlor, T. L. (2007). The role of spatial location in remembering and forgetting peripheral words. $\mathrm{Ca}$ nadian Journal of Experimental Psychology, 61, 91-101.

Hourihan, K. L., \& TAYlor, T. L. (2006). Cease remembering: Control processes in directed forgetting. Journal of Experimental Psychology: Human Perception \& Performance, 32, 1354-1365.

IVANOFF, J., \& TAYLOR, T. L. (2006). Inhibition of return promotes stopsignal inhibition by delaying responses. Visual Cognition, 13, 503512.

Kahneman, D. (1973). Attention and effort. Englewood Cliffs, NJ: Prentice Hall.

KuČERA, H., \& Francis, W. N. (1967). Computational analysis of present-day American English. Providence, RI: Brown University Press.

LogAN, G. D. (1983). On the ability to inhibit simple thoughts and actions: I. Stop-signal studies of decision and memory. Journal of Experimental Psychology: Learning, Memory, \& Cognition, 9, 585606.

LoGAN, G. D. (1985). On the ability to inhibit simple thoughts and actions: II. Stop-signal studies of repetition priming. Journal of Experimental Psychology: Learning, Memory, \& Cognition, 11, 675-691.

LogAN, G. D. (1994). On the ability to inhibit thought and action: A user's guide to the stop signal paradigm. In D. Dagenbach \& T. H. Carr (Eds.), Inhibitory processes in attention, memory, and language (pp. 189-239). San Diego: Academic Press.

LogAN, G. D., \& BARBER, C. Y. (1985). On the ability to inhibit complex thoughts: A stop-signal study of arithmetic. Bulletin of the Psychonomic Society, 23, 371-373.

MacLEOD, C. M. (1998). Directed forgetting. In J. M. Golding \& C. M. MacLeod (Eds.), Intentional forgetting: Interdisciplinary approaches (pp. 1-57). Mahwah, NJ: Erlbaum.

Marks, W., \& Dulaney, C. L. (2001). Encoding processes and attentional inhibition in directed forgetting. Journal of Experimental Psychology: Learning, Memory, \& Cognition, 27, 1464-1473.

McCormick, P. A. (1997). Orienting attention without awareness. Journal of Experimental Psychology: Human Perception \& Performance, 23, 168-180.

Neumann, E., \& DeSchepper, B. G. (1992). An inhibition-based fan effect: Evidence for an active suppression mechanism in selective attention. Canadian Journal of Psychology, 46, 1-40.

Posner, M. I., \& BoIes, S. J. (1971). Components of attention. Psychological Review, 78, 391-408.

Posner, M. I., \& Cohen, Y. (1984). Components of visual orienting. In H. Bouma \& D. G. Bouwhuis (Eds.), Attention and performance X: Control of language processes (pp. 531-556). Hillsdale, NJ: Erlbaum.

Pratt, J., Hillis, J., \& Gold, J. M. (2001). The effect of the physical characteristics of cues and targets on facilitation and inhibition. Psychonomic Bulletin \& Review, 8, 489-495.
Roediger, H. L., III, \& CRowder, R. G. (1972). Instructed forgetting: Rehearsal control or retrieval inhibition (repression)? Cognitive Psychology, 3, 244-254.

Samuel, A. G., \& Kat, D. (2003). Inhibition of return: A graphical meta-analysis of its time course and an empirical test of its temporal and spatial properties. Psychonomic Bulletin \& Review, 10, 897-906.

Schooler, L. J., \& HerTwig, R. (2005). How forgetting aids heuristic inference. Psychological Review, 112, 610-628.

TAYLOR, T. L. (2005). Inhibition of return following instructions to remember and forget. Quarterly Journal of Experimental Psychology, 58A, 613-629.

Wylie, G. R., FoXe, J. J., \& TAYLOR, T. L. (2008). Forgetting as an active process: An fMRI investigation of item-method-directed forgetting. Cerebral Cortex, 18, 670-682.

ZACKs, R. T., \& HASHER, L. (1994). Directed ignoring: Inhibitory regulation of working memory. In D. Dagenbach \& T. H. Carr (Eds.), Inhibitory processes in attention, memory, and language (pp. 241-264). San Diego: Academic Press.

Zacks, R. T., RadVAnsky, G., \& Hasher, L. (1996). Studies of directed forgetting in older adults. Journal of Experimental Psychology: Learning, Memory, \& Cognition, 22, 143-156.

Zbrodoff, N. J., \& LogAN, G. D. (1986). On the autonomy of mental processes: A case study of arithmetic. Journal of Experimental Psychology: General, 115, 118-130.

\section{NOTES}

1. Although the precise paradigms used to investigate directed forgetting come in many forms (for a review, see Basden \& Basden, 1998), the present investigation focused exclusively on what is called the item method.

2. Forgetting need not be active to facilitate performance in cognitive tasks: Schooler and Hertwig (2005) demonstrated that within the ACT $-\mathrm{R}$ cognitive architecture, even the passive decay of memory improved certain forms of heuristic inference.

3. The choice to use a $1,400-\mathrm{msec}$ instruction-go-signal SOA was predicated on Fawcett and Taylor's (2008) finding of a large F > R RT difference in response to visual probes presented at 1,400 and $1,800 \mathrm{msec}$ following instruction onset. Using a 1,400-msec instruction-go-signal SOA in the present study ensured that differential cognitive processes initiated by the $\mathrm{R}$ and $\mathrm{F}$ memory instructions were active during the presentation of the go signal (at 1,400 $\mathrm{msec}$ ) and remained active for at least the two shortest SSDs (i.e., for which the instruction-stop-signal delay was $1,600 \mathrm{msec}[1,400+200 \mathrm{msec}]$ and $1,800 \mathrm{msec}[1,400+$ $400 \mathrm{msec}]$ ).

(Manuscript received July 5, 2009; revision accepted for publication February 8, 2010.) 